\title{
Effects of cefuroxime axetil combined with Xingpi Yanger granules on the serum gastrin, motilin, and somatostatin levels in children with upper respiratory tract infection accompanied by diarrhea: results of a randomized trial
}

\author{
Xiaohong Ren ${ }^{1}$, Yuying Wang ${ }^{2}$, Zimeng He ${ }^{3}$, Hongli Liu ${ }^{4}$, Kun Xue ${ }^{1}$ \\ ${ }^{1}$ The Fifth Department of Pediatrics, Baoji Maternal and Child Health Hospital, Baoji, China; ${ }^{2}$ The Second Department of Pediatrics, Baoji \\ Maternal and Child Health Hospital, Baoji, China; ${ }^{3}$ Qilu Medical College of Shandong University, Jinan, China; ${ }^{4}$ Department of Pediatrics, \\ Northwest Women and Children Hospital, Xian, China \\ Contributions: (I) Conception and design: All authors; (II) Administrative support: All authors; (III) Provision of study materials or patients: All \\ authors; (IV) Collection and assembly of data: All authors; (V) Data analysis and interpretation: X Ren; (VI) Manuscript writing: All authors; (VII) \\ Final approval of manuscript: All authors. \\ Correspondence to: Yuying Wang. The Second Department of Pediatrics, Baoji Maternal and Child Health Hospital, 15 Jinger Road, Baoji 721000 , \\ China. Email: 492729104@qq.com.
}

Background: The purpose of the study was to investigate the effects of cefuroxime axetil combined with Xingpi Yanger granules on the treatment of upper respiratory tract infection accompanied by diarrhea and on serum gastrin (GAS), motilin (MOT), and somatostatin (SS) levels in children.

Methods: In total, 124 children with upper respiratory tract infection accompanied by diarrhea admitted to the department of pediatrics in our hospital from May 2019 to May 2020 were selected and divided into a study group ( $n=62)$ and a reference group ( $n=62)$, according to admission number. The reference group children received routine treatment, while the children in the study group were treated with cefuroxime axetil combined with Xingpi Yanger granules. After treatment, each clinical index of the children in both groups was detected to evaluate the clinical efficacy of the different treatment methods.

Results: There were no significant differences in gender ratio, average age, mean body temperature, mean duration of diarrhea, average weight, or place of residence between the 2 groups $(\mathrm{P}>0.05)$; the total clinical effective rate after treatment in the study group was significantly higher than that in the reference group $(\mathrm{P}<0.05)$; the dehydration correction time, antipyretic time, antidiarrheal time, and total treatment time in the study group were all significantly lower than those in the reference group $(\mathrm{P}<0.001)$; the serum GAS and MOT levels at T1, T2, and T3 in the study group were significantly lower than those in the reference group $(\mathrm{P}<0.001)$, whereas the SS levels at T1, T2, and T3 in the study group were significantly higher than those in the reference group $(\mathrm{P}<0.001)$; and the incidence of adverse reactions of the children in the study group was significantly lower than that in the reference group $(\mathrm{P}<0.05)$.

Conclusions: Cefuroxime axetil combined with Xingpi Yanger granules can significantly lower serum GAS, MOT, and SS levels and shorten treatment time in children with upper respiratory tract infection accompanied by diarrhea, with significant clinical efficacy and high safety, and is thus worthy of application and promotion.

Trial Registration: Chinese Clinical Trial Registry ChiCTR2100049234.

Keywords: Cefuroxime axetil; Xingpi Yanger granules; upper respiratory tract infection; diarrhea

Submitted Jul 05, 2021. Accepted for publication Aug 18, 2021.

doi: $10.21037 / \mathrm{tp}-21-314$

View this article at: https://dx.doi.org/10.21037/tp-21-314 


\section{Introduction}

Upper respiratory tract infection, defined as a generic term of acute inflammation in the nasal cavity, pharynx, or larynx, is a common acute respiratory infection $(1,2)$. Due to their still developing immune function, children have weaker protection against bacterial invasion, with those younger than 5 years old being susceptible to upper respiratory tract infection. Diarrhea is a common complication of upper respiratory tract infection in children. It is mainly caused by immune system disorder, bacterial invasion, or common colds, with those in critical condition occasionally suffering from convulsions, acute abdominal pain, or other effects, which cumulatively pose a significant threat to children's physical and mental health $(3,4)$. The risk of respiratory tract infection in children with diarrhea is significantly increased. According to related reports, under the same environmental conditions, the risk of respiratory tract infection in children with diarrhea is $28 \%$ higher than that in normal children. Cefuroxime axetil, a commonly used antibiotic drug has a good therapeutic effect on the treatment of upper respiratory tract infection precipitated by a variety of pathogenic bacteria. Xingpi Yanger granules are a Chinese patent medicine, whose activity includes clearing away heat and toxic materials, relieving diarrhea, nourishing the blood, and tranquilization, and can be used to treat acute and chronic diarrhea caused by intestinal flora disturbance. When using antibiotics to treat respiratory tract infections in children, antibiotics should be used regularly to avoid the occurrence of antibiotic resistance, and a series of side effects caused by excessive use of antibiotics should also be paid attention to. Pay attention to the combination of drug treatment and the increase of physical resistance to avoid over-treatment. With the aim providing a better reference for clinical treatment, we investigated the effects of cefuroxime axetil combined with Xingpi Yanger granules on the treatment of upper respiratory tract infection accompanied by diarrhea in children. We present the following article in accordance with the CONSORT reporting checklist (available at https:// dx.doi.org/10.21037/tp-21-314).

\section{Methods}

\section{General information}

A total of 124 children with upper respiratory tract infection accompanied by diarrhea admitted to the department of pediatrics in Baoji maternal and child health care hospital from May 2019 to May 2020 were enrolled and divided into a study group ( $n=62)$ and a reference group ( $n=62$ ), according to admission number. The study is a parallel study and allocation ratio is 1:1. All procedures performed in this study involving human participants were in accordance with the Declaration of Helsinki (as revised in 2013). The study was approved by ethics board of Baoji maternal and child health care hospital (No.: 2018121403) and informed consent was taken from all the patients.

\section{Inclusion criteria}

The inclusion criteria were as follows: (I) children met the diagnostic criteria of upper respiratory tract infection and diarrhea as outlined in the 17th edition of the Nelson Textbook of Pediatrics (5); (II) children had diarrhea lasting for more than 1 day and that required medical treatment; and (III) according to the conditions of approval mandated by the Hospital Ethics Committee, the children and their family members all signed the informed consent.

\section{Exclusion criteria}

The exclusion criteria were as follows: (I) children had severe diseases of the respiratory system, nervous system, or urinary system; (II) children had systemic infection or infections on other sites, and (III) children had poor mental status or treatment compliance and could not cooperate with others.

\section{Study methods}

In the reference group, the children received routine clinical treatment by the means of placing ice bags on children's heads, using ethanol to wipe the areas around the great vessels (e.g., the axilla, groin, neck), or advising them to drink more warm water $(6,7)$. In addition to physical cooling, the children were given ibuprofen suspension (State Food and Drug Administration approval number H19991011; Shanghai Johnson and Johnson Pharmaceutical Co., Ltd., Shanghai, China) orally no more than 4 times a day at $5-10 \mathrm{mg} / \mathrm{kg}$ until their body temperature returned to normal. The children were also given ribavirin granules (State Food and Drug Administration approval number H20066463; Sunflower Pharmaceutical Group Defeier Co., Ltd., Hengshui, China) orally, at $10 \mathrm{mg} / \mathrm{kg}, 3$ times a day, along with live combined Bifidobacterium and Lactobacillus tablets (State Food and Drug Administration approval number S19980004; Inner Mongolia Shuangqi Pharmaceutical Co., 
Table 1 Evaluation of clinical efficacy

\begin{tabular}{ll}
\hline Clinical efficacy & Symptoms \\
\hline Recovery & $\begin{array}{l}\text { After 1-2 days of treatment, the body temperature returned to normal, with no indication of further increase; the stool } \\
\text { frequency returned to normal, and symptoms of abdominal pain and diarrhea completely disappeared }\end{array}$ \\
$\begin{array}{l}\text { Marked } \\
\text { effectiveness }\end{array}$ & $\begin{array}{l}\text { After } 1-2 \text { days of treatment, the temperature returned to normal, but occasionally increased again; stool frequency } \\
\text { returned to normal, and the symptoms of diarrhea and abdominal pain disappeared }\end{array}$ \\
Effectiveness & $\begin{array}{l}\text { After } 2-3 \text { days of treatment, the body temperature decreased by more than } 1{ }^{\circ} \mathrm{C} \text { but did not return to normal, and the } \\
\text { frequency of diarrhea and severity of abdominal pain decreased significantly compared with the pretreatment period }\end{array}$ \\
Ineffectiveness & Children did not meet the above criteria and showed further deterioration
\end{tabular}

Total effective rate $=$ recovery rate + marked effectiveness rate + effectiveness rate.

Ltd., Inner Mongolia, China), 2 tablets each time and 3 times each day. In addition, depending on each child's condition, intravenous infusion was carried out to correct electrolyte levels and maintain acid-base balance $(8,9)$.

In addition to above treatment in the control group, the children in the study group were administered cefuroxime axetil dispersible tablets (State Food and Drug Administration approval number H20030854; Guangzhou Nucien Pharmaceutical Co., Ltd., Guangzhou, China) 0.125 $\mathrm{g}$ each time, twice each day. Furthermore, the children were also given Xingpi Yanger granules (State Food and Drug Administration approval number Z20025415; Guizhou Jianxing Pharmaceutical Co., Ltd, Guiyang, China); the granules were mixed with warm water. The administration protocol for the Xingpi Yanger granules was follows: children younger than 1 year: $2 \mathrm{~g}$ each time and twice each day; children aged 1-2 years old: $4 \mathrm{~g}$ each time and twice each day: children aged 3-6 years old: $4 \mathrm{~g}$ each time and 3 times per day. The children in both groups underwent 3 consecutive treatment cycles, with 1 cycle lasting 3 days.

\section{Observation indices}

The evaluation of clinical efficacy is detailed in Table 1. The dehydration correction time, antipyretic time, antidiarrheal time, and total treatment time were recorded and compared between the 2 groups (secondary outcome). Five milliliters of fasting venous blood was collected from the children in both groups before treatment (T0), 1 day after treatment (T1), 3 days after treatment (T2), and 7 days after treatment (T3). After centrifugation, the upper serum was collected, and gastrin (GAS) (primary outcome), motilin (MOT) expression levels (primary outcome) in the serum samples were detected by using a multimode reader (HEDSY96S, Shandong Horde Electronic Technology Co.,
Ltd., Weifang, China) with auxiliary kits. Meanwhile, the somatostatin (SS) levels (primary outcome) were acquired by radioimmunoassay. The adverse reactions between the 2 groups were also compared.

\section{Statistical methods}

All study data were processed for statistical analysis by SPSS 21.0 software (IBM Corporation, Armonk, NY, USA), and GraphPad Prism 7 (GraphPad Software, San Diego, CA. USA) was used to visualize the data. Measurement data are expressed by $(\bar{x} \pm s)$, and were analyzed by $t$-test. Enumeration data are expressed as numbers and percentages and were analyzed by $\chi^{2}$ test. A P value $<0.05$ indicated a statistically significant difference.

\section{Results}

\section{Comparison of clinical data between the 2 groups}

Figure 1 showed the participant flow of this study. There were no significant differences in gender ratio, average age, mean body temperature, mean duration of diarrhea, average weight, and place of residence between the 2 groups ( $\mathrm{P}>0.05)$, and the groups were thus comparable (Table 2$)$.

\section{Comparison of clinical efficacy between the 2 groups}

The total clinical effective rate after treatment in the study group was significantly higher than that in the reference group $(\mathrm{P}<0.05)$, as shown in Table 3.

\section{Comparison of clinical improvement between the 2 groups}

The dehydration correction time, antipyretic time, antidiarrheal time, and total treatment time in the study 


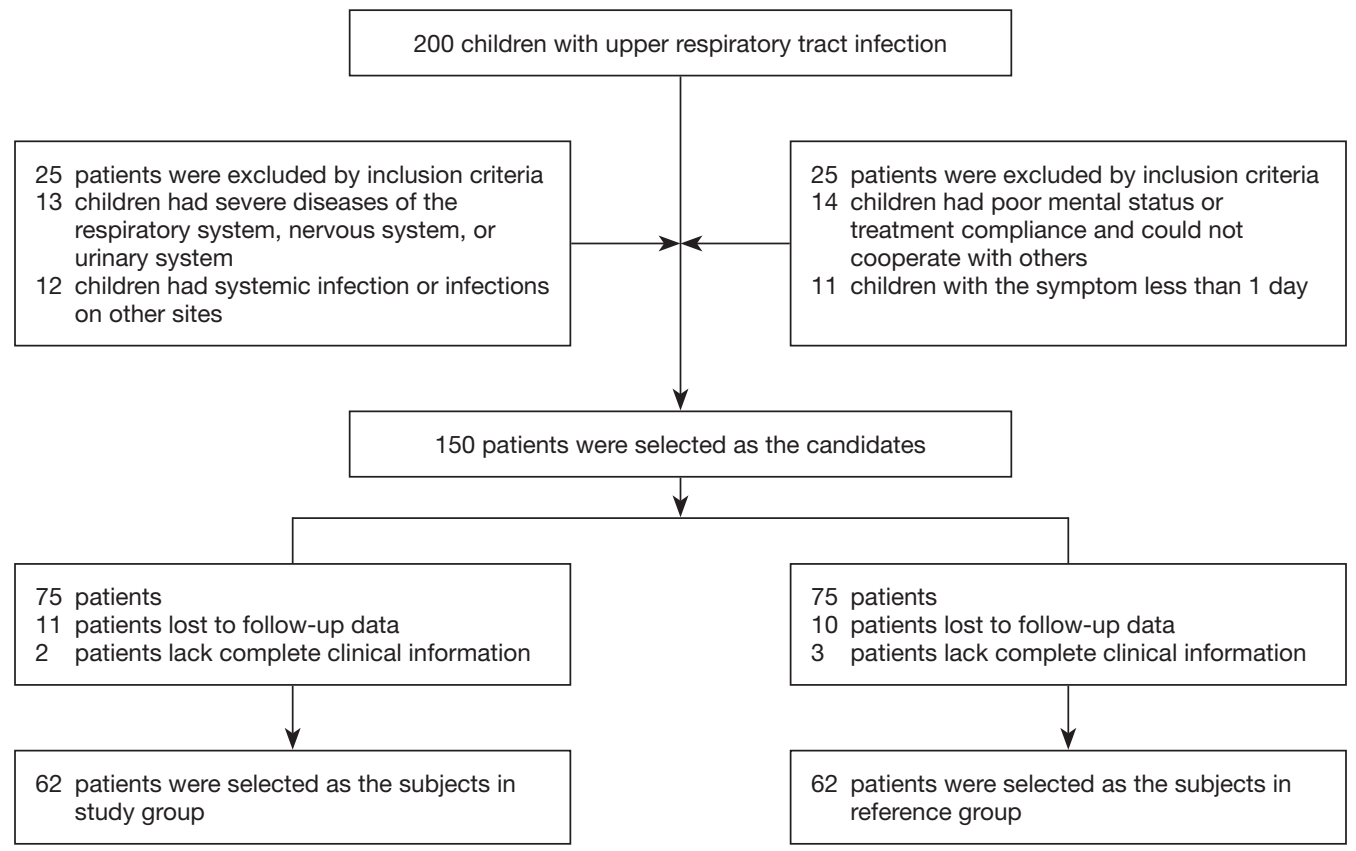

Figure 1 Participant flow of this study.

Table 2 Comparison of clinical data between the 2 groups

\begin{tabular}{|c|c|c|c|c|}
\hline Types & Study group $(n=62)$ & Reference group $(\mathrm{n}=62)$ & $\chi^{2} / t$ & $\mathrm{P}$ \\
\hline Male & $35(56.45 \%)$ & $33(53.23 \%)$ & & \\
\hline Female & $27(43.55 \%)$ & $29(46.77 \%)$ & & \\
\hline Average age (years old) & $2.18 \pm 1.33$ & $2.23 \pm 1.08$ & 0.230 & 0.819 \\
\hline Mean duration of diarrhea (d) & $1.27 \pm 0.26$ & $1.31 \pm 0.22$ & 0.925 & 0.357 \\
\hline Average weight (kg) & $12.24 \pm 2.53$ & $12.29 \pm 2.48$ & 0.111 & 0.912 \\
\hline Place of residence & & & 0.131 & 0.717 \\
\hline Urban area & $28(45.16 \%)$ & $26(41.94 \%)$ & & \\
\hline
\end{tabular}

Table 3 Comparison of clinical efficacy between the two groups [n (\%)]

\begin{tabular}{lcccccc}
\hline Group & $\mathrm{n}$ & Recovery & Marked effectiveness & Effectiveness & Ineffectiveness & Total effective rate \\
\hline Study group & 62 & $19(30.65 \%)$ & $28(45.16 \%)$ & $12(19.35 \%)$ & $3(4.84 \%)$ & $95.16 \%(59 / 62)$ \\
Reference group & 62 & $10(16.13 \%)$ & $22(35.48 \%)$ & $18(29.03 \%)$ & $12(19.35 \%)$ & $80.65 \%(50 / 62)$ \\
$\chi^{2}$ & & & & & 9.043 \\
$\mathrm{P}$ & & & & & 0.003 \\
\hline
\end{tabular}

Total effective rate $=$ recovery rate + marked effectiveness rate + effectiveness rate . 
Table 4 Comparison of clinical improvement between the 2 groups $(x \pm s, d)$

\begin{tabular}{lccccc}
\hline Group & $\mathrm{n}$ & Dehydration correction time & Antipyretic time & Antidiarrheal time & Total treatment time \\
\hline Study group & 62 & $1.16 \pm 0.42$ & $1.13 \pm 0.38$ & $1.52 \pm 0.41$ & $5.82 \pm 1.73$ \\
Reference group & 62 & $1.75 \pm 0.36$ & $1.62 \pm 0.29$ & $1.94 \pm 0.44$ & $8.22 \pm 1.63$ \\
$\mathrm{t}$ & 8.398 & 8.071 & 5.499 & 7.950 \\
$\mathrm{P}$ & 0.000 & 0.000 & 0.000 & 0.000 \\
\hline
\end{tabular}

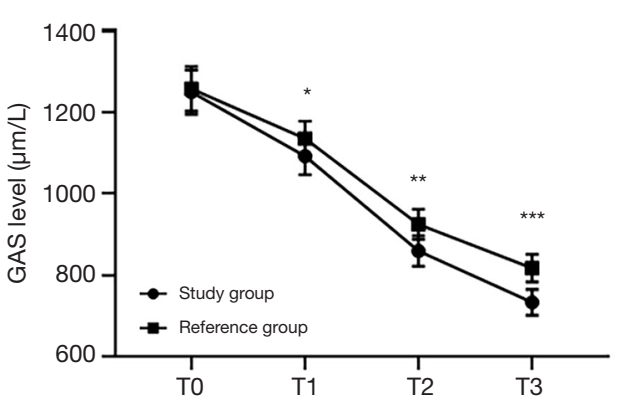

Figure 2 Comparison of serum GAS levels at different time points between the 2 groups $\left(\bar{x}_{ \pm} \mathrm{s}\right)$. The abscissa represents T0, T1, T2, and T3, while the ordinate represents GAS level. The GAS levels at T0, T1, T2, and T3 in the study group were $1,249.35 \pm 54.33$, $1,092.46 \pm 45.38,859.45 \pm 37.43$, and $733.63 \pm 31.64 \mu \mathrm{g} / \mathrm{L}$, respectively. The GAS levels at T0, T1, T2, and T3 in the reference group were $1,257.46 \pm 54.59,1,135.77 \pm 42.49,925.31 \pm 36.78$, and $817.52 \pm 33.98 \mu \mathrm{g} / \mathrm{L}$, respectively. *, indicates that there were significant differences in the GAS levels at $\mathrm{T} 1$ between the 2 groups $(\mathrm{t}=5.486 ; \mathrm{P}<0.000)$. **, indicates that there were significant differences in the GAS levels at $\mathrm{T} 2$ between the 2 groups $(\mathrm{t}=9.882 ; \mathrm{P}=0.000)$. ${ }^{* * *}$, indicates that there were significant differences in the GAS levels at T3 between the 2 groups ( $\mathrm{t}=14.227 ; \mathrm{P}=0.000)$.

group were all significantly lower than those in the reference group $(\mathrm{P}<0.05)$, as shown in Table 4 .

\section{Comparison of serum GAS levels at different time points between the 2 groups}

There were significant differences in the GAS levels at T1, $\mathrm{T} 2$, and $\mathrm{T} 3$ between the 2 groups $(\mathrm{P}<0.05)$, as shown in Figure 2.

\section{Comparison of MOT levels at different time points between the 2 groups}

There were significant differences in the MOT levels at

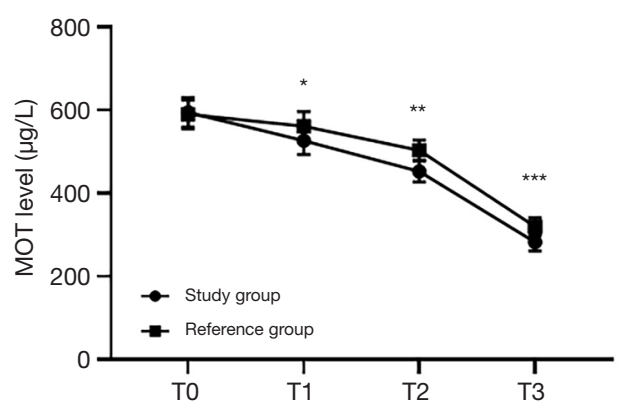

Figure 3 Comparison of MOT levels at different time points between the 2 groups $(\bar{x} \pm \mathrm{s})$. The abscissa represents T0, T1, T2 and T3, while the ordinate represents MOT level. The MOT levels at T0, T1, T2, and T3 in the study group were $594.35 \pm 36.17$, $526.47 \pm 33.49,452.33 \pm 25.48$, and $282.34 \pm 21.37 \mu \mathrm{g} / \mathrm{L}$, respectively. The MOT levels at T0, T1, T2, and T3 in the reference group were $589.47 \pm 34.15,561.26 \pm 34.87,503.26 \pm 24.35$, and $319.55 \pm 21.69 \mu \mathrm{g} / \mathrm{L}$, respectively. *, indicates that there were significant differences in the MOT levels at $\mathrm{T} 1$ between the 2 groups $(\mathrm{t}=5.666 ; \mathrm{P}<0.000)$. **, indicates that there were significant differences in the MOT levels at $\mathrm{T} 2$ between the 2 groups $(\mathrm{t}=11.378 ; \mathrm{P}=0.000)$. ${ }^{* *}$, indicates that there were significant differences in the MOT levels at T3 between the 2 groups ( $\mathrm{t}=9.622 ; \mathrm{P}=0.000)$.

$\mathrm{T} 1$, $\mathrm{T} 2$, and $\mathrm{T} 3$ between the 2 groups $(\mathrm{P}<0.05)$, as shown in Figure 3.

\section{Comparison of SS levels at different time points between the 2 groups}

There were significant differences in the SS levels at T1, T2, and T3 between the 2 groups $(\mathrm{P}<0.05)$, as shown in Figure 4.

\section{Comparison of adverse reactions between the 2 groups}

The total incidence of adverse reactions of the patients in the study group was significantly lower than that in the 


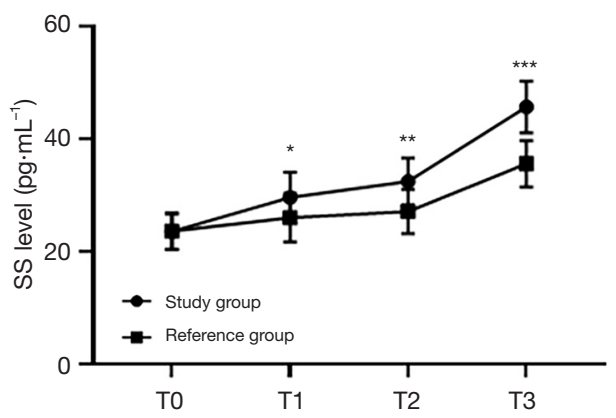

Figure 4 Comparison of SS levels at different time points between the 2 groups $\left(\bar{x}_{ \pm}\right)$. The abscissa represents T0, T1, T2, and T3, while the ordinate represents the SS level. The SS levels at T0, $\mathrm{T} 1, \mathrm{~T} 2$, and $\mathrm{T} 3$ in the study group were $23.56 \pm 3.17,29.62 \pm 4.51$, $32.46 \pm 4.18$, and $45.72 \pm 4.57 \mathrm{pg} / \mathrm{mL}$, respectively. The SS levels at $\mathrm{T} 0, \mathrm{~T} 1, \mathrm{~T} 2$, and $\mathrm{T} 3$ in the reference group were $23.63 \pm 3.21$, $26.02 \pm 4.31,27.11 \pm 3.91$, and $35.61 \pm 4.21 \mathrm{pg} / \mathrm{mL}$, respectively. *, indicates that there were significant differences in the SS levels at T1 between the 2 groups $(\mathrm{t}=4.544 ; \mathrm{P}<0.000)$. **, indicates that there were significant differences in the SS levels at T2 between the 2 groups $(\mathrm{t}=7.360 ; \mathrm{P}=0.000) .{ }^{* * *}$, indicates that there were significant differences in the SS levels at T3 between the 2 groups $(\mathrm{t}=12.812$; $\mathrm{P}=0.000)$.

reference group $(\mathrm{P}<0.05)$, as shown in Figure 5 .

The number of cases of anaphylaxis, photophobia, and rash were 1,2 , and 1 , respectively, in the study group; and 5, 6 and 2 , respectively, in the reference group.

There were significant differences in the total incidence of adverse reactions between the 2 groups $\left(\chi^{2}=6.279\right.$; $\mathrm{P}=0.012$ ).

\section{Discussion}

Upper respiratory tract infection is mainly caused by the invasion of various pathogenic bacteria, including viruses and bacteria, and studies have reported that most children are subject to secondary bacterial infection; therefore, the combination of antiviral and antibacterial therapy should be carried out in clinical treatment (10-12). Additionally, upper respiratory tract infection is characterized by a critical onset and high recurrence rate-reaching up to over 10 times annually—which seriously affects children's growth, development, and their daily life. Treatment of this disease has thus become a major concern of pediatricians (13-15). In addition, the invasion of pathogenic bacteria incurred by upper respiratory tract infection can also lead to immune

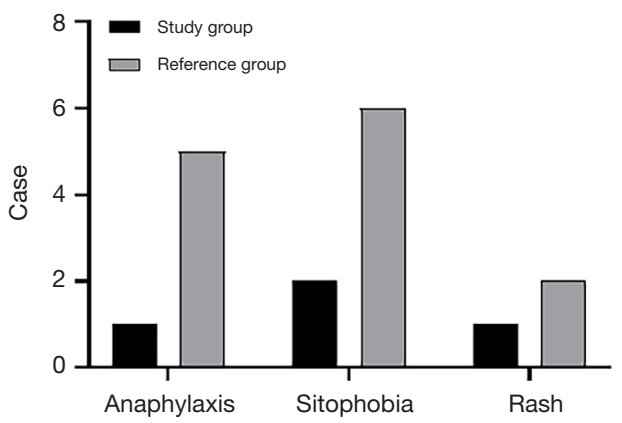

Figure 5 Comparison of adverse reactions between the 2 groups [n (\%)]. The abscissa represents anaphylaxis, sitophobia, and rash, while the ordinate represents the case.

system disorders, which mainly manifest as an alteration in intestinal flora, meaning diarrhea is a common complication of upper respiratory tract infection. The affected children with diarrhea mostly present with increased frequency of defecation, changed stool shapes, and, in some severe cases, are even accompanied by different degrees of vomiting, abdominal pain, and other symptoms, or dehydration caused by an acid-base imbalance in their bodies (16). Generally, children with diarrhea have an acute and rapid progression; consequently, timely targeted drug treatment according to children's clinical symptoms should be conducted to improve treatment effects.

Moreover, the regulation of the balance of intestinal flora should be prioritized in the treatment of upper respiratory tract infection accompanied by diarrhea in children $(17,18)$. Xingpi Yanger granules, are a commonly used Chinese medicinal compound preparation for the treatment of upper respiratory tract infection in children. This compound has fewer side effects and higher clinical safety than do other drugs and exerts the effects of invigorating the spleen to eliminate dampness, regulating intestinal hormones and enhancing stronger adsorption of pathogenic bacteria, reducing the damage of pathogenic bacteria to the intestinal gastric mucosa to a certain extent, relieving intestinal clinical symptoms, and promoting the treatment of diarrhea (19-21). Cefuroxime axetil is a cephalosporin antibiotic, and its mechanism of action is to inhibit the synthesis of the bacterial cell wall by covalently binding to bacterial transpeptidase, which leads to bacterial death; it can also bind to penicillin to inhibit the formation of the bacterial cross-linking wall in the proliferation phase and kill bacteria in the reproduction phase; therefore, it is often used to treat upper respiratory tract infection caused by various 
bacteria. Cefuroxime axetil has good oral absorption and broad-spectrum antibacterial activity. Cefuroxime axetil has been widely used in the treatment of upper respiratory tract infections and diarrhea. The treatment of cefuroxime axetil in patients with upper respiratory tract infection and diarrhea can effectively remove bacteria in patients with good tolerance, safe and reliable curative effect, and has important clinical application value $(22,23)$. GAS and MOT increased and SS decreased in children with pneumonia secondary diarrhea, indicating that there were changes in gastrointestinal hormones in children with diarrhea. Gastrointestinal hormones can significantly affect the secretion, movement and absorption of gastrointestinal tract, biliary tract and pancreas, and play a certain role in the pathophysiology of diarrhea. Xingpi Yanger granule has obvious regulatory effect on GAS, MOT and SS in children with pneumonia secondary diarrhea. The clinical effect of Xingpi Yanger granule was good, and the serum gastrin, plasma motilin and somatostatin were close to normal after treatment. MOT can stimulate the motility of intestinal smooth muscles, GAS is a hormone secreted by the mucosa of the small intestine that can increase the secretion of gastric acid and the contraction of antrum, and SS is a common inhibitory hormone that can reduce the basal level of gastric acid and relieve the peristalsis of the gastrointestinal tract in patients to some extent (24). In this study, the results revealed that serum GAS and MOT levels at T1, T2, and T3 in the study group were significantly lower than those in the reference group, whereas the SS levels at T1, T,2 and T3 in the study group were significantly higher than those in the reference group, indicating that cefuroxime axetil combined with Xingpi Yanger granules could lower serum GAS and MOT levels, improve SS levels, delay the peristalsis of the gastrointestinal tract, and reduce the occurrence of diarrhea. Pedata et al. (25) reported that after the children with pneumonia accompanied by diarrhea were treated with Xingpi Yanger granules, the serum MOT levels after treatment $(448.71 \pm 13.42 \mu \mathrm{g} / \mathrm{L})$ were significantly lower than those before treatment $(583.29 \pm 42.66 \mu \mathrm{g} / \mathrm{L})$, indicating that Xingpi Yanger granules can inhibit the secretion of serum MOT and improve intestinal function in children.

In conclusion, cefuroxime axetil combined with Xingpi Yanger granules can effectively improve gastrointestinal function in children with upper respiratory tract infection accompanied by diarrhea with significant clinical efficacy and high safety, and is thus worthy of application and promotion.

\section{Acknowledgments}

Funding: None.

\section{Footnote}

Reporting Checklist: The authors have completed the CONSORT reporting checklist. Available at https://dx.doi. org/10.21037/tp-21-314

Trial Protocol: Available at https://dx.doi.org/10.21037/tp21-https://dx.doi.org/10.21037/tp-21-314

Data Sharing Statement: Available at https://dx.doi. org/10.21037/tp-21-314

Conflicts of Interest: All authors have completed the ICMJE uniform disclosure form (available at https://dx.doi. org/10.21037/tp-21-314). The authors have no conflicts of interest to declare.

Ethical Statement: The authors are accountable for all aspects of the work in ensuring that questions related to the accuracy or integrity of any part of the work are appropriately investigated and resolved. All procedures performed in this study involving human participants were in accordance with the Declaration of Helsinki (as revised in 2013). The study was approved by ethics board of Baoji maternal and child health care hospital (No.: 2018121403) and informed consent was taken from all the patients.

Open Access Statement: This is an Open Access article distributed in accordance with the Creative Commons Attribution-NonCommercial-NoDerivs 4.0 International License (CC BY-NC-ND 4.0), which permits the noncommercial replication and distribution of the article with the strict proviso that no changes or edits are made and the original work is properly cited (including links to both the formal publication through the relevant DOI and the license). See: https://creativecommons.org/licenses/by-nc-nd/4.0/.

\section{References}

1. Qiao XF, Wang GP, Li X, et al. Analysis of the clinical effect of olfactory training on olfactory dysfunction after upper respiratory tract infection. Acta Otolaryngol 2019;139:643-6.

2. Nguyen D, Barrs VR, Kelman M, et al. Feline upper 
respiratory tract infection and disease in Australia. J Feline Med Surg 2019;21:973-8.

3. Kauna R, Sobi K, Pameh W, et al. Oral Rehydration in Children with Acute Diarrhoea and Moderate Dehydration-Effectiveness of an ORS Tolerance Test. J Trop Pediatr 2019;65:583-91.

4. Vorilhon P, Arpajou B, Vaillant Roussel H, et al. Efficacy of vitamin $\mathrm{C}$ for the prevention and treatment of upper respiratory tract infection. A meta-analysis in children. Eur J Clin Pharmacol 2019;75:303-11.

5. Iverson A, Meyer CJ, Vogel P, et al. Efficacy of Aminomethyl Spectinomycins against Complex Upper Respiratory Tract Bacterial Infections. Antimicrob Agents Chemother 2019;63:e02096-18.

6. Sandre MK, Poenaru SM, Boggild AK. Erythema Nodosum Leprosum Triggered by Antecedent Influenza Vaccine and Respiratory Tract Infection: A Case Report. J Cutan Med Surg 2019;23:114-6.

7. Kasela M, Grzegorczyk A, Malm A. Molecular Diversity of Staphylococcus aureus Colonizing the Upper Respiratory Tract of Residents and Staff in A Nursing Home. Pol J Microbiol 2019;68:371-6.

8. Wang L, Zhou Y, Wang X, et al. Mechanism of Asbt (Slc10a2)-related bile acid malabsorption in diarrhea after pelvic radiation. Int J Radiat Biol 2020;96:510-9.

9. Shang H, Bai T, Chen Y, et al. Outcomes and implications of diarrhea in patients with SARS-CoV-2 infection. Scand J Gastroenterol 2020;55:1049-56.

10. Yanai S, Nakamura S, Kawasaki K, et al. Immune checkpoint inhibitor-induced diarrhea: Clinicopathological study of 11 patients. Dig Endosc 2020;32:616-20.

11. Jung SM, Lee H, Yang Y, et al. Quantifying the causal impact of funding bedside antigen testing on the incidence of respiratory syncytial virus infection in Japan: a difference-in-differences study. Ann Transl Med 2020;8:1441.

12. Rathod P, Mori D, Parmar R, et al. Co-processing of cefuroxime axetil by spray drying technique for improving compressibility and flow property. Drug Dev Ind Pharm 2019;45:767-74.

13. Lalge R, Thipsay P, Shankar VK, et al. Preparation and evaluation of cefuroxime axetil gastro-retentive floating drug delivery system via hot melt extrusion technology. Int J Pharm 2019;566:520-31.

14. Ongkasin K, Sauceau M, Masmoudi Y, et al. Solubility of cefuroxime axetil in supercritical CO2: Measurement and modeling. The Journal of Supercritical Fluids 2019;152:104498-1-104498-7.
15. David S, Cunningham R. Echinacea for the prevention and treatment of upper respiratory tract infections: A systematic review and meta-analysis. Complement Ther Med 2019;44:18-26.

16. Haruma K, Kamada T, Manabe N, et al. Old and New Gut Hormone, Gastrin and Acid Suppressive Therapy. Digestion 2018;97:340-4.

17. Song S, Li X, Geng C, et al. Somatostatin stimulates colonic MUC2 expression through SSTR5-NotchHes1 signaling pathway. Biochem Biophys Res Commun 2020;521:1070-6.

18. Wu N, Yin N, Zhang Y, et al. Somatostatin receptor 5 -mediated modulation of outward $\mathrm{K}+$ currents in rat retinal ganglion cells. Neuroreport 2020;31:131-8.

19. Guenter R, Aweda T, Carmona Matos DM, et al. Overexpression of somatostatin receptor type 2 in neuroendocrine tumors for improved Ga68-DOTATATE imaging and treatment. Surgery 2020;167:189-96.

20. Lukomska A, Dobrzanski G, Liguz-Lecznar M, et al. Somatostatin receptors (SSTR1-5) on inhibitory interneurons in the barrel cortex. Brain Struct Funct 2020;225:387-401.

21. Liu Q, Johnson EM, Lam RK, et al. Peripheral TREM1 responses to brain and intestinal immunogens amplify stroke severity. Nat Immunol 2019;20:1023-34.

22. Tang C, Ding R, Sun J, et al. The impacts of natural polysaccharides on intestinal microbiota and immune responses - a review. Food Funct 2019;10:2290-312.

23. Shanmugasundaram U, Critchfield JW, Giudice LC, et al. Parallel studies of mucosal immunity in the reproductive and gastrointestinal mucosa of $\mathrm{HIV}$-infected women. Am J Reprod Immunol 2020;84:e13246.

24. Kashiwagi S, Naito Y, Inoue R, et al. Mucosa-Associated Microbiota in the Gastrointestinal Tract of Healthy Japanese Subjects. Digestion 2020;101:107-20.

25. Pedata P, Ricci G, Malorni L, et al. In vitro intestinal epithelium responses to titanium dioxide nanoparticles. Food Res Int 2019;119:634-42.

(English Language Editor: J. Gray)

Cite this article as: Ren X, Wang Y, He Z, Liu H, Xue K. Effects of cefuroxime axetil combined with Xingpi Yanger granules on the serum gastrin, motilin, and somatostatin levels in children with upper respiratory tract infection accompanied by diarrhea: results of a randomized trial. Transl Pediatr 2021;10(8):2106-2113. doi: 10.21037/tp-21-314 